\title{
The Way of the Integration of Economics \& Management Subject Competition and Experimental Teaching
}

\author{
Benxin Lao \\ National Demonstration Center for Experimental Economics and Management Education \\ (Guangxi University of Finance and Economics), Nanning, 530003, China
}

Keywords: the way of the integration, subject competition, experimental teaching.

\begin{abstract}
As an important part of practical education in colleges and universities, subject competition plays an important role in promoting the cultivation of application-oriented talents in economics \& management school. In view of the disadvantages caused by the failure of integrating subject competition in the experimental teaching system in the present university of economics and management, this paper puts forward three ways to integrate subject competition and experiment teaching.
\end{abstract}

\section{经管类学科竞赛与实验教学相融合的路径}

\author{
劳本信 \\ 经济与管理国家级实验教学示范中心（广西财经学院），南宁，530003
}

关键词: 融合路径; 学科竞赛; 实验教学

摘 要: 学科竞赛作为高等院校实践性环节的重要组成部分, 对经管类应用型人才的培养具有 很好的推动作用。本文针对目前经管类高校学科竞赛没有纳入实验教学体系所带来的弊端提 出了经管类学科竞赛与实验教学相融合的3种路径。

\section{1. 引言}

学科竞赛是在紧密结合课堂教学的基础上又高于课堂教学水平的, 以竞赛的方式考查学生 某学科基本理论知识和解决实际问题能力的活动 ${ }^{[1]}$ 。学科竞赛作为高等院校实践性环节的重 要组成部分, 对培养学生创新思维和团队合作精神具有很好的推动作用, 对经管类应用型人 才的培养尤为重要。[2][3]

\section{2. 国内经管类学科竞赛呈现的特点}

目前，经管类或与经管学科相关的大学生竞赛具有多层次、多种类，官办和民办并存，以 及认定标准不一致等特点。

\section{1 多层次, 多种类}

在层次上，包括国际性竞赛，例如国际企业管理挑战赛(简称GMC)、“尖锋时刻”商业模拟 大赛 (全球) 等; 两岸三地竞赛，例如“国泰安杯”商业精英挑战赛; 全国性竞赛，例如“互联 网+”大学生创新创业大赛、全国大学生管理模拟决策比赛、全国高等院校企业竞争模拟大赛、 全国大学生商业银行技能大赛等; 还有省级竞赛和校级竞赛等。

在种类上, 有创新创业类大赛, 例如“互联网+”大学生创新创业大赛、“挑战杯”中国大学生 
创业计划竞赛等; 也有企业经营管理综合模拟类大赛，例如全国大学生管理模拟决策比赛、 全国高等院校企业竞争模拟大赛、全国大学生创业综合模拟大赛等; 还有专业技能类大赛, 例如全国大学生商业银行技能大赛、全国大学生市场调查分析大赛、全国高校市场营销大赛、 全国大学生物流设计大赛、全国大学生电子商务竞赛、全国大学生会展策划大赛、全国大学 生信息化会计技能竞赛等。

\section{2 官办和民办并存}

1) 官办大赛。这是指由教育部、教育部高教司、教育厅等国家教育行政管理部门主办的竞 赛, 例如 “互联网+”大学生创新创业大赛、“挑战杯”中国大学生创业计划竟赛、全国大学生数 学建模竞赛等。

2) 半官办大赛。这是指由教育部下属专业教学指导委员会和学会、协会、联席会等机构主 办的竞赛, 例如电子商务类专业教学指导委员会主办的全国大学生电子商务“创新、创意及创 业”挑战赛，经济与贸易类专业教学指导委员会主办的全国高校商业精英挑战赛“国泰安杯”营 销模拟决策竞赛，等等。

3) 民办。这是指企业或民间机构主办的大赛, 例如, 中国物流生产力促进中心主办的全国 大学生物流仿真设计大赛, 由于该学会未在科协、民政部注册, 只能算是民办竞赛。CESIM 公司主办的 “尖峰时刻”全国商业模拟竞赛, 虽然覆盖全球逾百个国家, 国内也有许多顶尖高 校参赛, 但主办单位是企业或国内某一所高校, 没有官方或半官方公章, 一般也会被认定为 民办性质。

\section{3 认定标准不一致}

1) 赛事级别认定不科学、不合理。在各高校中, 赛事级别认定依据的是主办单位有行政级 别, 以及是否为教育行政管理部门。一些学科竞赛, 虽然竞争激励, 难度系数大, 含金量大, 但由于是企业或社会团体主办的, 证书上没有教育行政部门的公章, 在许多高校并没有获得 认可, 赛事级别会被低格认定。例如, 商道的“创新创业”全国管理决策模拟大赛、“尖峰时刻” 商业模拟大赛, 大赛举办历史长, 参赛高校数量多, 竞争激励程度高, 但因为没有官方公章 而被降格认定，甚至不被认定。

2) 赛事级别认定标准不清。在一些高校中, 同样是教育部高等学校教学指导委员会主办的 竞赛中, 有的被认定为国家级竞赛, 例如电子商务类专业教学指导委员会主办的全国大学生 电子商务挑战赛，物流类专业教学指导委员主办的全国大学生物流设计大赛; 而有的会被认 定为省级赛事, 例如经济与贸易类专业教学指导委员会主办的全国高校商业精英挑战赛, 旅 游管理类专业教学指导委员会主办的全国大学生会展创意大赛。还有更为特殊的例子, 例如 “航信杯”财税技能大赛全国总决赛由航天信息股份公司主办, 按企业主办的性质应被认定为 厅级赛事, 但其省赛在广西却又是由自治区教育厅主办的, 按官方主办的性质却又应该被认 定为省级赛事。

另外, 由于缺乏赛事级别的认定标准, 同样的一项经管类学科竞赛, 在各高校之间的级别 认定也存在很多差异, 这给参赛学生和指导老师都带来了许多困扰。

\section{3. 国内经管类学科竞赛组织开展中存在的问题}

\section{1 学生参赛的积极性不同, 参赛面不广}

学生参加学科竞赛不是必修教学项目, 许多学生迫于院系或老师的压力应付参加, 效果不 甚理想。一些学生认为即使参加了也不一定能出线, 更别说获奖, 付出了努力和牺牲了个人 时间可能也得不到有效的回报, 认为参赛对自己没有实质性的帮助, 所以学生参赛的积极性 并不高。另外, 由于经费的约束、名额的限制, 学科竞赛活动无法在学生中广泛开展普及, 学生的受益面偏小, 导致学生参与度不高, 参赛人数有限。[4] 


\section{2 老师参与指导的积极性不同}

高校现在普遍重科研, 轻教学。老师指导学科竞赛虽然也有一定的奖励或报酬, 但远远不 能激发大多数老师的积极性。很多老师不愿花费时间和精力在学科竞赛上, 因为这会影响到 自己的科研工作。有的学校或省份对老师评职称比较重视学科竞赛成果, 这或许能激发老师 的积极性, 而在大多数高校或省份中, 教学成果尚且无法等同于科研成果, 更别说指导学生 学科竞赛的成果了, 所以愿意用心参与学科竞赛指导的老师数量非常有限, 特别是一些高学 历、高学位、高职称的老师不愿意参与。

\section{3 师生为赛而赛, 相关知识和技能缺乏系统性教学}

本来组织学科竞赛的目的在于让学生在参与的过程中提高自己的实践和创新能力, 但是, 由于学科竞赛没有融入实践教学体系, 学校组织参赛是为了获得荣誉, 老师指导竞赛、学生 参加竞赛也是为了赢得荣誉与奖励。这必然导致大家一起违背学科竞赛的初衷, 过于注重结 果, 轻视参与过程。指导老师和学生更多关注的是竞赛技巧、规则漏洞、空门绝招等, 忽视 了学科竞赛的知识拓展和专业能力的锻炼本质, 没有达到学科竞赛预期的效果, 没有形成人 人参与、共同提高的局面。[5]

\section{4 缺乏长效管理机制}

学科竞赛的管理体系不够完善。由于学科竞赛没有纳入教学体系, 学科竞赛均属于临时性 工作, 不是教务处和各院系固定的工作任务, 除个别指导老师能经常组织学生进行训练之外, 并没有一套长效的管理机制。另外, 一些经管类高校的实验教学资源采取集中管理的模式, 该模式虽然可以提高实验室综合利用率，但对开放性教学并不有利。指导老师或学生每一次 使用实验室进行赛前训练都要经历复杂的申请手续。实际上, 即使是一些国家级实验教学示 范中心, 实验室面对学生开放的状况也不乐观。

以上问题, 究其原因, 都是因为学科竞赛没有较好的融入实验教学体系中。

\section{4. 经管类学科竞赛与实验教学融合路径的建议}

为了解决上述问题和矛盾, 必须加强经管类学科竞赛与实验教学相融合, 促进经管类专业 教、赛、学一体化发展。[6][7][8]

\section{1 教学内容融合}

教学内容的融合就是把学科竞赛的内容与课程教学内容相融合, 结合学科竞赛设置相匹配 的实验课程, 例如, “互联网+”、“小挑”、“大创项目”等学科竞赛可以与《创业设计》、《创 业计划设计》等课程相融合; “学创杯”创业综合模拟大赛、“尖峰时刻”商业模拟竞赛、全国 管理决策模拟大赛、全国企业竞争模拟大赛等可以与《企业经营管理综合模拟实验》、《企 业管理决策模拟实验》、《ERP沙盘模拟对抗》、《企业竞争仿真模拟》等课程相融合; 一 些专业学科竞赛与一些专业实验课程相融合, 例如全国电子商务大赛与《电子商务实验》融 合, 全国生市场调查分析大赛与《市场调研实验》融合, 将教学内容、排课时间与竞赛需求 进行匹配，教学与竞赛相互促进，协同进行。

\section{2 激励机制融合}

1) 建立学生参赛激励机制。在学科竞赛与课程设置相匹配之后, 将学科竞赛纳入教学体系, 参加大赛的学生可以获得相应课程的加分, 获得特定奖励级别的学生可以免试等。如果某些 学科竞赛没有相应的课程匹配, 就与创新创业实践学分、课外拓展学分等挂钩, 参赛者根据 其成本计算相应的学分。另外, 除了竞赛本身的奖励之外, 学校或二级学院对获奖学生可以 给予奖学金、学习与实践评优加分, 并多加宣传, 让学生获得更多的荣誉感。

2) 建立指导老师激励机制。目前各高校建立的针对指导老师的激励机制主要三种, 一是根 
据指导获奖的级别给予奖励; 二是将教师指导学生学科竞赛和科技创新活动记入教学工作量, 与课时量一起计算课酬; 三是采取教改课题立项的方式给予经费资助, 以获奖来结题。三种 方式各有优点: 教学奖励的方式重结果, 学生没有获奖, 老师就没有奖励, 有经验的老师不 怕带学生, 没有经验的老师压力就比较大; 计入教学工作量方式可以较好平衡与科研工作的 矛盾, 因为指导学科竞赛的老师可以减少其它教学工作量; 教改课题立项和经费资助的方式 比较重过程, 老师的责任感更强, 指导过程就有经费可以使用, 而且课题成果对评职称有用。

\section{3 管理体系融合}

完善和健全的管理体系是深入开展学科竞赛活动的重要保障。首先, 以教务处为领导单位, 二级学院为执行单位, 团委为协办单位, 建立统一的学科竞赛管理体系。每个二级学院成立 一个指导老师团队和一个学科竞赛学生社团（协会），学生协会下面再成立分部，建立起一 个学科竞赛学生自我管理组织。学生协会下的每个分部负责一项学科竞赛, 对应至少一位指 导老师。要培养学生骨干分子发挥带头和示范作用, 采取同学教同学、老队员带新队员的方 式形成梯队, 抱团学习, 有计划、有步骤地进行进阶训练, 从而极大地调动学生群体参与学 科竞赛的积极性，同时也可以缓解指导老师力量不足的矛盾。

\section{5. 结论}

以广西财经学院为例, 通过经管类学科竞赛与实验教学相融合的一些尝试, 我们在创新创 业类大赛、企业经营管理综合模拟类大赛和专业技能大赛方面, 均取得了不错的成绩。更重 要的是, 学生的参赛面非常广, 2018年报名参加创新创业类大赛的学生达到10000多名学生, 报名参加“企业经营管理沙盘模拟大赛”的学生达到 1500 多人, 学生与老师参赛的积极性都大 大提升了。

\section{致谢}

本文获得经济与管理国家级实验教学示范中心（广西财经学院）和广西财经学院经管类专 业创新创业开放性教学模式研究课题的资助。

\section{参考文献}

[1] 刘丽,朱晓林,马晓琳.加强学科竟界建设打造经济管理类创新型人才培养的实践教学平台田. 课程教育研究,2014(3):27-28.

[2] 倪端.基于学科竞赛的经管类应用型人才的培养[J].中国电力教育,2010(28):5-6

[3] 李晈.基于学科竞赛的经管类专业实践教学改革与研究[J].教育教学论坛,2016(13):66-67

[4] 陈鹏.学科竞赛嵌入经管类专业实践教学体系探索与实践 [J].中国商论2017(5):189-191

[5] 陶敏. 经管类学科竞赛对大学生创新能力培养的促进研究[J]. 中小企业管理与科技2017(12): 94-95

[6] 李虹.经管类专业教赛学一体化创新实验区建设与实践 $[J]$. 现代教育技术,2013(12): 118-122

[7] 刘梅娟.经济管理类学科竞赛研究与分析[J].财会通讯,2013(3):126-128

[8] 宋爽.独立院校经管类专业教赛学一体化体系建设[J].现代商贸工业,2014(6) :148-148 